\title{
Cylindrocladium pteridis em Palmeiras Ornamentais
}

\author{
Gilson S. Silva1 ${ }^{1}$ Acelino C. Alfenas ${ }^{2}$, Rafael F. Alfenas ${ }^{2}$ \& Edival V. Zauza² \\ ${ }^{1}$ Universidade Estadual do Maranhão, Departamento de Fitotecnia e Fitossanidade, CEP 65001-970, São Luís, MA, \\ e-mail: gilson_soares@uol.com.br; ${ }^{2}$ Universidade Federal de Viçosa, Departamento de Fitopatologia, CEP 36571-000, \\ Viçosa, MG, e-mail: aalfenas@ufv.br
}

(Aceito para publicação em 28/07/2004)

Autor para correspondência: Gilson Soares da Silva

\author{
ABSTRACT \\ Cylindrocladium pteridis on Ornamental Palms \\ Cylindrocladim pteridis is first described as causal agent of leaf blight on Washingtonia filifera and Veitchia merrilli \\ in the State of Maranhão, Brazil. The fungus was isolated in vitro and identified based on its morphological characteristics.
}

\begin{abstract}
As palmeiras ornamentais são amplamente utilizadas em projetos paisagísticos, tanto urbano quanto em jardins particulares, alcançando, algumas delas, elevados preços no mercado. Durante o ano de 2003, diversas amostras da palmeira da Califórnia [Washingtonia filifera (L.) Wendl.] foram recebidas para análise no Laboratório de Fitopatologia da Universidade Estadual do Maranhão. Plantas jovens apresentavam folhas com manchas encharcadas (anasarca), medindo até $1 \mathrm{~cm}$ de diâmetro (Figura 1A) que, quando coalesciam atingiam grandes porções do limbo. Na face abaxial das folhas, sobre as lesões, era possível observar abundante esporulação do patógeno. Lâminas preparadas a partir de raspagem direta das lesões revelaram a presença de um fungo do gênero Cylindrocladium o qual foi facilmente cultivado em meio de BDA. O patógeno foi identificado como C. pteridis Wolf, com base nas características morfológicas de conídios, dos conidióforos e vesículas (Figura 1C), de acordo com Crous \& Wingfield (A monography of Cylindrocladium, including anamorphs of Calonectria, Mycotaxon 51:341-435. 1994). Embora a fase teliomórfica do fungo tenha sido descrita como Calonectria pteridis Crous, Wingfield \& Alfenas (Mycotaxon 46:228. 1993), no presente estudo, estruturas sexuais do fungo não foram encontradas. Em inspeções realizadas em floriculturas e viveiros de plantas ornamentais, verificou-se que a mesma doença ocorria em Palmeira de Manilla [Veitchia merrilli (Becc) H.E. Moose] causando manchas necróticas de coloração marronavermelhadas, afetando grandes áreas do tecido foliar (Figura 1B). Testes de patogenicidade em mudas de palmeira da Califórnia e palmeira de Manilla comprovaram a etiologia da doença. Cylindrocladium pteridis tem sido ralatado em representantes da família Palmae no Brasil, tais como coqueiro (Cocos nucifera L.) (Silva \& Sousa, Fitopatologia Brasileira 6:515-517.1981), Mauritia flexuosa L. (Silva, Fitopatologia Brasileira 21:523.1996), Cariota mitis Loureiro (Coelho Netto et al., Fitopatologia Brasileira 28:569. 2003). Este é o primeiro
\end{abstract}

relato de C. pteridis causando doença em $W$. filifera e Veitchia merrilli no Brasil.

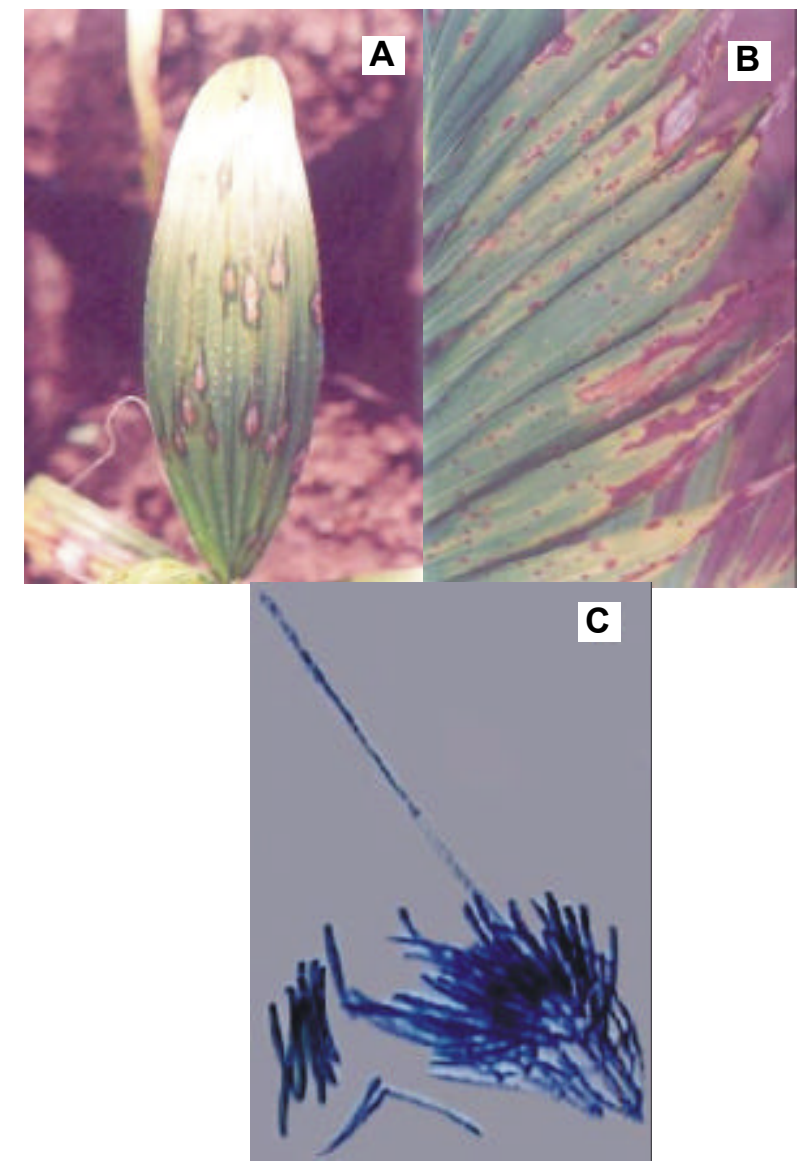

FIG. 1 - Sintomas de Cylindrocladium pteridis em palmeiras ornamentais. A- manchas em folhas de Washingtonia filifera; B - manchas em folhas de Veitchia merrilli; C - Estruturas típicas de C. pteridis. 